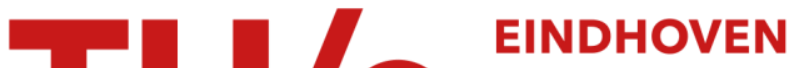 UNIVERSITY OF TECHNOLOGY
}

\section{Simple and efficient scanning tunneling luminescence detection at low-temperature}

\section{Citation for published version (APA):}

Keizer, J. G., Garleff, J. K., \& Koenraad, P. M. (2009). Simple and efficient scanning tunneling luminescence detection at low-temperature. Review of Scientific Instruments, 80(12), 123704-1/5.

https://doi.org/10.1063/1.3274675

DOI:

10.1063/1.3274675

Document status and date:

Published: 01/01/2009

\section{Document Version:}

Publisher's PDF, also known as Version of Record (includes final page, issue and volume numbers)

\section{Please check the document version of this publication:}

- A submitted manuscript is the version of the article upon submission and before peer-review. There can be important differences between the submitted version and the official published version of record. People interested in the research are advised to contact the author for the final version of the publication, or visit the $\mathrm{DOI}$ to the publisher's website.

- The final author version and the galley proof are versions of the publication after peer review.

- The final published version features the final layout of the paper including the volume, issue and page numbers.

Link to publication

\section{General rights}

Copyright and moral rights for the publications made accessible in the public portal are retained by the authors and/or other copyright owners and it is a condition of accessing publications that users recognise and abide by the legal requirements associated with these rights.

- Users may download and print one copy of any publication from the public portal for the purpose of private study or research.

- You may not further distribute the material or use it for any profit-making activity or commercial gain

- You may freely distribute the URL identifying the publication in the public portal.

If the publication is distributed under the terms of Article 25fa of the Dutch Copyright Act, indicated by the "Taverne" license above, please follow below link for the End User Agreement:

www.tue.nl/taverne

Take down policy

If you believe that this document breaches copyright please contact us at:

openaccess@tue.nl

providing details and we will investigate your claim. 


\title{
Simple and efficient scanning tunneling luminescence detection at low-temperature
}

\author{
J. G. Keizer, J. K. Garleff, and P. M. Koenraad \\ Department of Applied Physics, Eindhoven University of Technology, P.O. Box 513, 5600 MB Eindhoven, \\ The Netherlands
}

(Received 18 September 2009; accepted 23 November 2009; published online 28 December 2009)

\begin{abstract}
We have designed and built an optical system to collect light that is generated in the tunneling region of a low-temperature scanning tunneling microscope. The optical system consists of an in situ lens placed approximately $1.5 \mathrm{~cm}$ from the tunneling region and an ex situ optical lens system to analyze the emitted light, for instance, by directing the light into a spectrometer. As a demonstration, we measured tip induced photoluminescence spectra of a gold surface. Furthermore, we demonstrate that we can simultaneously record scanning tunneling microscope induced luminescence and topography of the surface both with atomic resolution. (c) 2009 American Institute of Physics.

[doi:10.1063/1.3274675]
\end{abstract}

\section{INTRODUCTION}

Briefly after the introduction of the scanning tunneling microscope (STM) as an instrument to study (semi)conductive surfaces at the atomic scale by Binnig et al. ${ }^{1,2}$ in 1982 , it was realized that its high spatial resolution can be extended into the optical domain. Six years later, light emission from the STM was reported by Coombs et al. ${ }^{3}$ and Gimzewski et $a{ }^{4}{ }^{4}$ In scanning tunneling microscopy luminescence (STL) photons created by the recombination of injected minority carriers in semiconductive samples ${ }^{5}$ or by the decay of a locally excited plasmon state on metallic samples ${ }^{6}$ are collected and analyzed. Since the processes of luminescence emission are governed by the position and size of the STM tip, STL has the potential to study the optical properties of a surface on the atomic scale. Several STL-modes of operation have been reported in literature ranging from relatively straight forward intensity measurements ${ }^{7,8}$ to spectral and spatial resolved photon mapping. ${ }^{6,9}$ In the latter technique luminescence spectra are collected during scanning, resulting in a map of spectra which can be directly linked to the topographic information. In this paper we report the adaptation of a commercially available Omicron low temperature STM for this purpose. Test measurements are performed on an $\mathrm{Au}(110)(1 \times 3)$ reconstructed surface. We demonstrate that it is possible to simultaneously record topography and spectrally resolved photon maps with atomic resolution with the employed luminescence collection system. Although, the current paper describes the implementation of a STM induced luminescence collection system in a widely used Omicron low temperature STM, the design is easily adapted to fit other types of STMs such as "beetle" STMs. ${ }^{10}$

\section{INSTRUMENT DESIGN}

\section{A. Scanning tunneling microscope}

The STM used is a commercially available Omicron low temperature STM that can be operated at $\mathrm{LN}_{2}$ and LHe temperature. The Omicron SPM PRE 4 is used as a current pre- amplifier. This preamplifier allows the amplification of tunneling currents up to $333 \mathrm{nA}$. The STM is used in conjunction with the Omicron MATRIX control platform. The Omicron low temperature STM consists of a preparation chamber $\left(p<5 \times 10^{-10}\right.$ mbar $)$ in which the samples and tips can be prepared, and a measuring chamber $(p<5$ $\times 10^{-12} \mathrm{mbar}$ ), which houses the STM head. The entire system is placed on a structurally isolated platform which physically decouples the STM from the building to reduce unwanted vibrations.

\section{B. Collection system}

The collection system we designed consists of two parts: two in situ lenses each providing an optical access point, see Fig. 1, and an ex situ optical collection system, see Fig. 2. The STM head of the Omicron low temperature STM provides two optical access points that are tilted at an angle of $20^{\circ}$ toward the sample face, see Fig. 1, which hold the in situ lenses. The diameter of the used lenses (Thorlabs al2520, $f=20.0 \mathrm{~mm}$, numerical aperture $=0.543$ ) was trimmed to 10 $\mathrm{mm}$ to fit a special designed lens holder which in turn fits into the optical access point on the STM head. The lenses were selected to direct the STM-induced luminescence in a parallel bundle through a viewport out of the vacuum chamber. At the moment, only one of the arms is used for luminescence collection. We plan to use the other arm in future excitation experiments. Once outside the vacuum chamber the bundle enters a lens system where it is narrowed and focused onto an optical fiber. The whole ex situ optical system consists of a charge coupled device (CCD) camera, three lenses, diaphragm, beamsplitter, collimator, fiber, and monochromator, see Fig. 2. Once the luminescence is coupled into the optical fiber (Thorlabs, $d=600 \mu \mathrm{m}$ ) it is directed into a monochromator, Acton Research Corporation SpectraPro$300 \mathrm{i}$, which is fitted with a liquid nitrogen cooled 576 $\times 384 \mathrm{Si}$ CCD camera operated at $100 \mathrm{~K}$. In order to ease alignment, the lens system was designed with three translational and two rotational degrees of freedom, see Fig. 3. The 


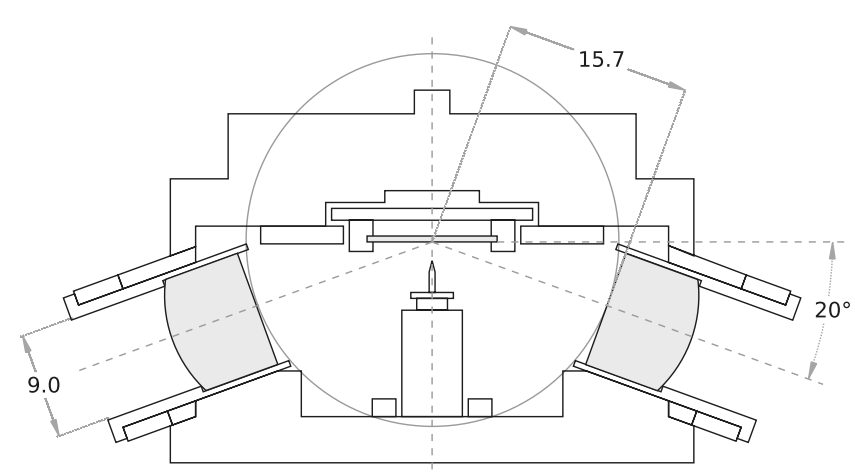

FIG. 1. Schematic representation of the STM head of the Omicron low temperature STM. The head provides two optical access points, which in our design are used to each hold one of the lenses in the vacuum.

five degrees of freedom facilitate the focusing of the beam onto the fiber. Although not necessary for STM-induced luminescence collection, the beam splitter (8:92) and CCD camera have the advantage that they allow visual tracking of the tip during coarse approach with a resolution of approximately $2 \mu \mathrm{m}$. In Fig. 4, a screenshot of the STM tip and its reflection on the sample surface is shown. The STM and the entire collection system, including the monochromator, are place inside a box to reduce unwanted collection of stray light.

The main advantage of the current design compared with a similar state-of-the-art lens detection system ${ }^{11}$ is its simplicity; only one in situ lens has to be installed on the STM head, making the use of any moveable parts inside the vacuum chamber redundant. In addition, the fact that the lens is mounted directly on the STM head, which is cooled, eliminates the need to install an additional cooling system to prevent radiative heating of the STM by the lens and its holder/ stage. Since in situ moving parts and additional cooling systems are unnecessary in the current design, the system is relatively robust, low cost, and straightforward to install. Due to the use of ex situ real free space optics, the fixed in situ lens does not restrict the luminescence collection to a specific point inside the STM head and allows greater freedom in the ex situ optical analysis. In fact, the five degrees of freedom of the ex situ free space optics allow luminescence collection from $\mathrm{a} \approx 4 \times 4 \times 4 \mathrm{~mm}^{3}$ volume, allowing the use of a variety of sample holders. Another advantages of the current design over others is the presence of a second in situ lens, see Fig. 1, which can be used separately from the lens that is used for luminescence collection. This opens the pos-

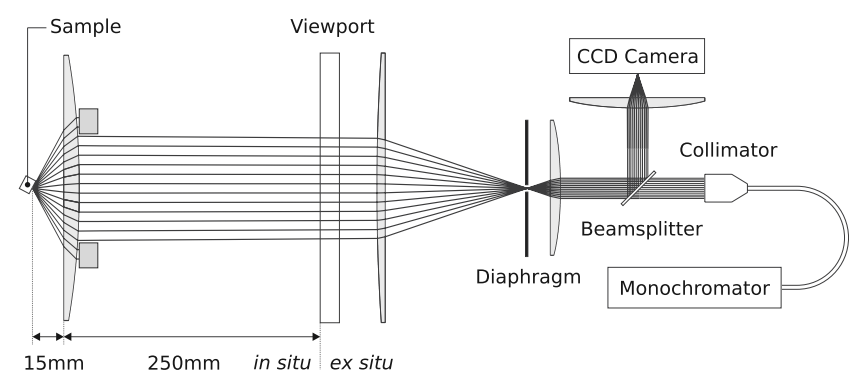

FIG. 2. Schematic representation of the complete optical system. The optical system is divided into an in situ and an ex situ part.

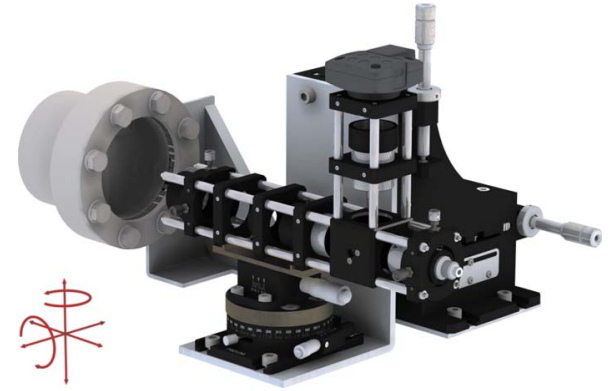

FIG. 3. (Color online) 3D-rendering of the ex situ part of the collection system. The collection system is bolted to the viewport of the measuring chamber (left). The five degrees of freedom of the system are indicated by the arrows.

sibility to do excitation experiments such as low temperature tip enhanced Raman spectroscopy. The ability to do polarized measurements without the need to install in situ polarization filters and rotation mounts is a further advantage of the current and other designs ${ }^{11-14}$ over designs that employ an in situ optical fiber to collect the luminescence. ${ }^{8,15,16}$

\section{Detection efficiency}

Analysis of the detection efficiency can be split into two parts: (1) collection yield of the first optical component and (2) collection efficiency of the remainder of the optical system. In our case the first optical component is the in situ lens, which has a diameter of $10 \mathrm{~mm}$ and is placed $15.7 \mathrm{~mm}$ from the tunnel contact. This results in a collection solid angle of $\approx 0.3 \mathrm{sr}$, which corresponds to $\approx 4.8 \%$ of the hemisphere. In order to quantify the collection efficiency of the remainder of the optical system we assume that each electron that is injected by the tip induces a plasmon which decays radiatively with a quantum efficiency of $1 \times 10^{-4}$. ${ }^{6,17-20}$ Given the collection yield of the in situ lens, this implies that at a current setpoint of $10 \mathrm{nA}$ a total of $\approx 1.5 \times 10^{5}$ photons s$^{-1}$ enter the optical system. At this current setpoint we achieved count rates up to $4 \times 10^{4} \mathrm{~s}^{-1}$. Thus, the efficiency of the collection system is estimated to be $\approx 27 \%$. It should be noted that this value includes the losses in the monochromator and the detection efficiency of Si CCD camera in the wavelength range $500-750 \mathrm{~nm}$. At the cost of the spectral information the collection efficiency can be greatly increased by using a photomultiplier. Given the collection yield of the in situ lens and the estimated collection efficiency of the optical system, the total detection efficiency, i.e., the number of collected photons divided by the number of total emitted photons, is estimated to be $\approx 1.3 \%$, which is comparable to the estimated

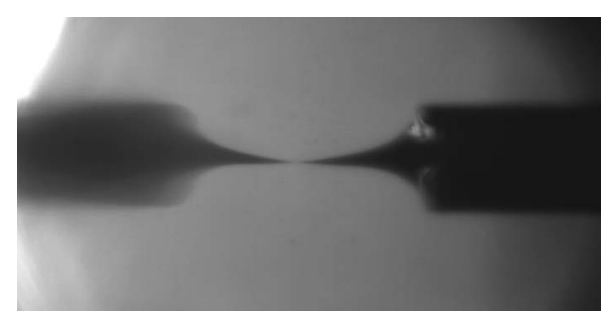

FIG. 4. CCD camera screenshot of the STM tip and its reflection (left) on the sample surface. The base of the tip is $250 \mu \mathrm{m}$ wide. 
collection yield values $(\approx 2.5 \%)$ of the lens detection system described by Hoffmann et al. ${ }^{11}$

\section{Experimental procedure}

In order to spatially resolve the tip induced luminescence signal, the normal STM topography mode is interrupted at a grid of points. During these interruptions of topography scanning, the feedback loop is kept on resulting in the tip being fixed at a constant height above the surface. In this static situation the luminescence signal is collected. The advantage of this procedure is that both the topography and luminescence information can be extracted in one scan, eliminating the influence of drift and consequently the need for a post- scan overlay correction of topography and luminescence data. The topography information is typically collected at scan speeds in the order of $50 \mathrm{~nm} / \mathrm{s}$ and the duration of the scan interruptions for luminescence collection is at the order of one second during which a few thousands of electrons are collected, comparable to count rates reported elsewhere in literature. ${ }^{21-25}$ For a $50 \times 50 \mathrm{~nm}^{2}$ image consisting of 500 topography lines and a $100 \times 100$ luminescence grid the total measuring time would amount to approximately $3 \mathrm{~h}$. Note that the time needed for measuring the topography amounts only to $10 \%$ of the total measuring time.

\section{EXPERIMENTAL RESULTS}

The sample measured consisted of a clamped glass plate on which an approximately $1 \mu \mathrm{m}$ thick gold layer was deposited. The sample was exposed to ambient conditions during transfer to the STM. In order to remove possible contaminants, the sample was heated to $150{ }^{\circ} \mathrm{C}$ in the preparation chamber before transfer to the measuring chamber. All measurement presented here were done at a temperature of $5 \mathrm{~K}$. Electrochemically etched tungsten tips were used. $^{26}$ The tips were heated in the preparation chamber to approximately $1200 \mathrm{~K}$ and subsequently bombarded with argon ions to remove the oxide layer.

A first result of the luminescence measurements is shown in Fig. 5, which shows a photon map of a 40 $\times 40 \mathrm{~nm}^{2}$ area of the gold surface (top) and a typical luminescence spectrum (bottom). The data was collected at $V=$ $+3.2 \mathrm{~V}$ and $I=100 \mathrm{nA}$. The photon map consists of 90 $\times 90$ pixels. Each pixel of the photon map is obtained by integrating the individual spectra over the wavelength range of $500-750 \mathrm{~nm}$. The average photon count rate is approximately $1.5 \times 10^{3}$ counts $/ \mathrm{s}$.

As it turned out the surface in the current measurement is a $\mathrm{Au}(110)$ surface with a $(1 \times 3)$ surface reconstruction. This is illustrated in Fig. 6, which shows a $100 \times 100 \mathrm{~nm}^{2}$ topography image (top), $V=0.8 \mathrm{~V}$ and $I=500 \mathrm{pA}$ of the gold surface and a schematic side view of the $\mathrm{Au}(110)(1$ $\times 3)$ reconstruction. The $(1 \times 3)$ reconstruction is clearly visible; the peak to peak distance is $1.2 \mathrm{~nm}$, which is in agreement with the value, $1.26 \mathrm{~nm}$, reported in literature. ${ }^{27}$ The diagonal line in the images is not a scan artifact but a dislocation in the gold surface.

In order to test the spatial resolution of the luminescence emission measurement we analyzed a photon map that was

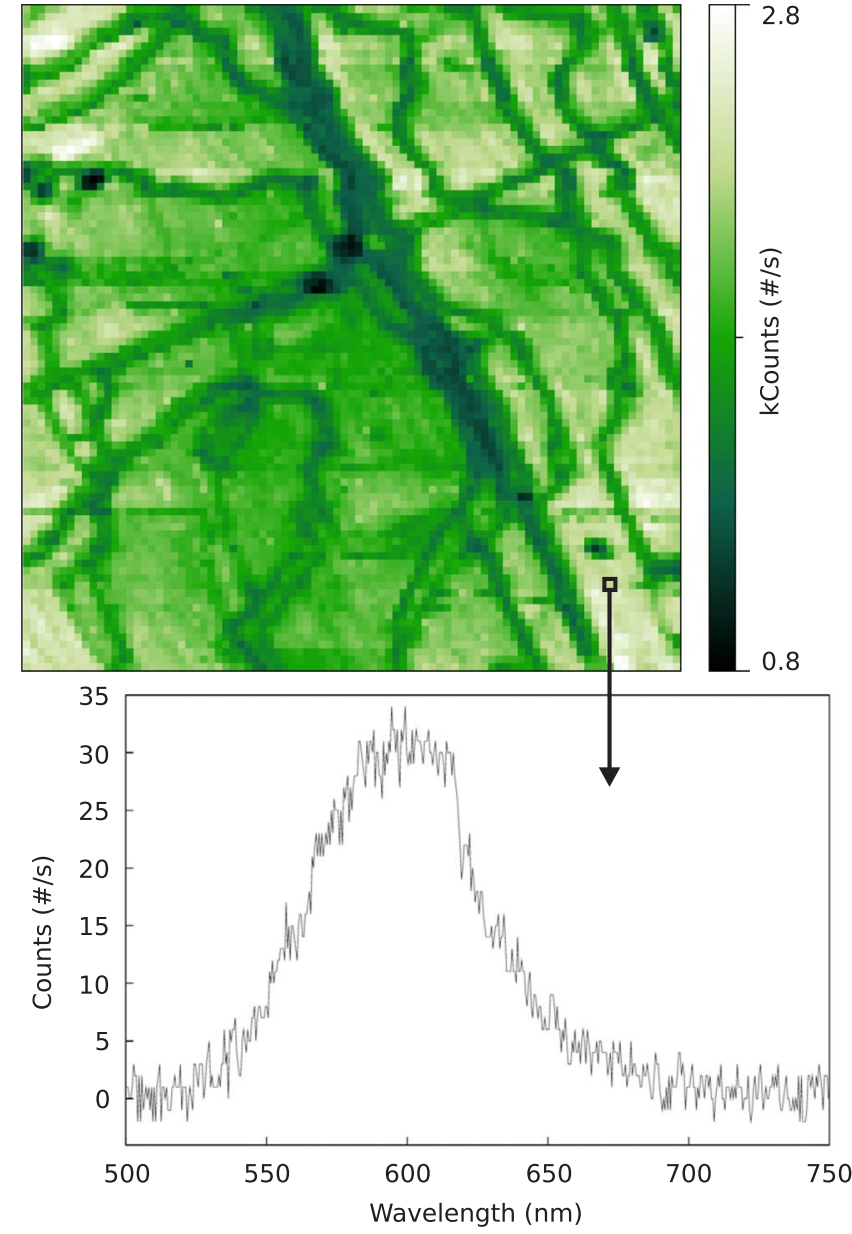

FIG. 5. (Color online) Photon map of a $40 \times 40 \mathrm{~nm}^{2}$ area of the Au surface (top) and a typical spectrum (bottom). The photon map was generated by integrating the recorded counts over the wavelength range of 500-750 $\mathrm{nm}$. $V=+3.2 \mathrm{~V}$ and $I=100 \mathrm{nA}$.

simultaneously recorded with both a topography and a current image which show the $(1 \times 3)$ reconstruction on the sample surface. In Fig. 7 the results are depicted. In the topography image (left) the $(1 \times 3)$ reconstruction is again clearly visible. This is also the case in the current image (middle) and more interesting also in the photon map (right). Comparison between the three rules out the possibility that the atomic resolution in the luminescence measurement is due to over- or undershoot of the tip during scanning; white regions (undershoot, increased current) and dark regions (overshoot, decreased current) at the step edges and dislocation lines in the current image (indicate by the arrows) both result in a decrease in the luminescence emission, see Fig. 7. Therefore, we conclude that current variations, $\pm 15 \%$, imposed by the settings of the feedback loop are of little importance for luminescence measurements on this sample system.

To further investigate the spatial resolving power in the luminescence signal, we compared an averaged line section of the topography of the $\mathrm{Au}(110)(1 \times 3)$ surface with the corresponding averaged line section in the photon map, see Fig. 8. The peaks and troughs on the plateau in the topography signal (solid line) correspond to the peaks and troughs in the luminescence signal (dashed line). The dotted vertical 

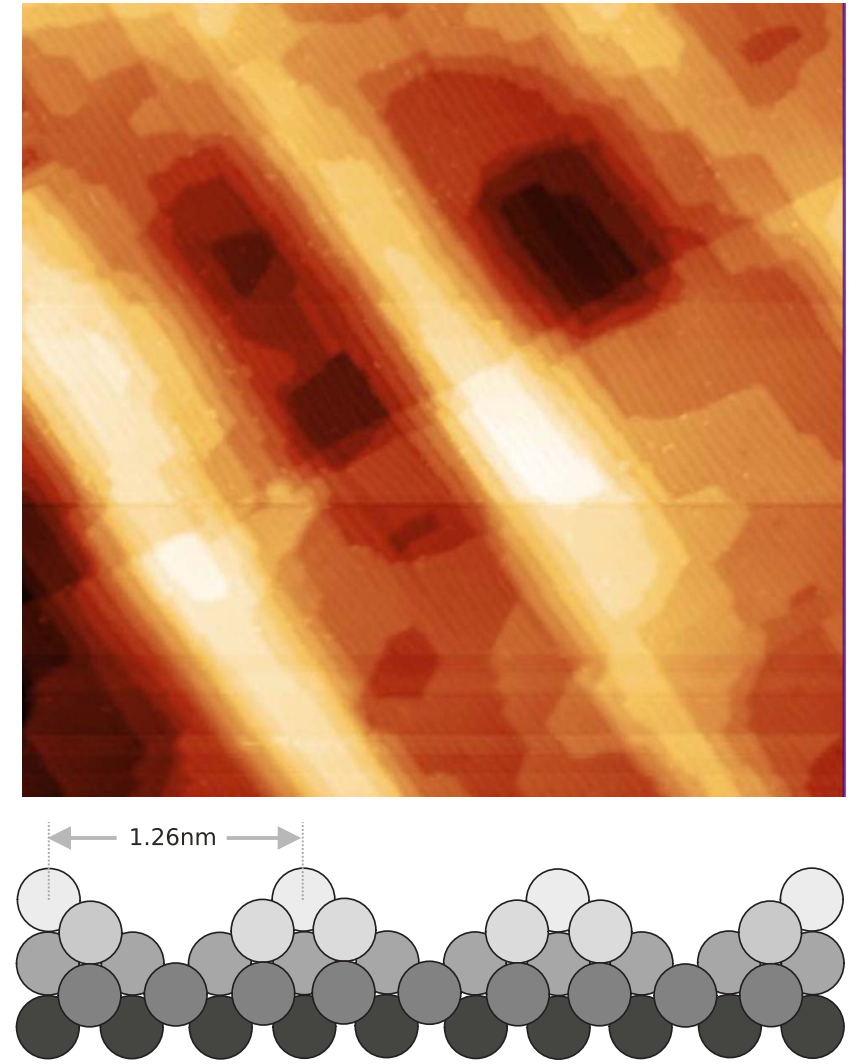

FIG. 6. (Color online) $100 \times 100 \mathrm{~nm}^{2}$ topography image (top) of the $\mathrm{Au}(110)(1 \times 3)$ surface taken at $V=+0.8 \mathrm{~V}$ and $I=0.5 \mathrm{nA}$ and schematic side view (bottom) of the $(1 \times 3)$ surface reconstruction.

lines indicate the theoretical periodicity, $1.26 \mathrm{~nm}$ of the surface reconstruction. As can be seen this is in good agreement with both the topography and luminescence data. Multiple explanations are given in literature to explain the increased luminescence on top of the atomic rows. One of them ascribes it to the modulation of the electromagnetic coupling in the cavity formed by the tip and sample ${ }^{6,28}$ and another to changes in emission spectra, and thus in intensity, due to different excitation mechanisms. ${ }^{29,30}$ However, a recently put forward model by Hofmann et al. ${ }^{9}$ might provide the best explanation at the moment. In this model the luminescence intensity modulations, both at a step edge and on the atomic
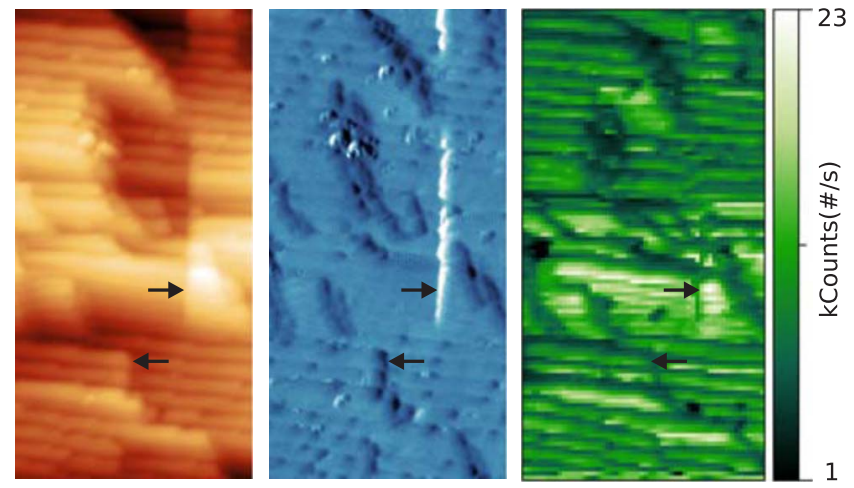

FIG. 7. (Color online) $25 \times 50 \mathrm{~nm}^{2}$ topography image (left), current image (middle), and photon map (right) of the $\mathrm{Au}(110)(1 \times 3)$ surface reconstruction taken at $V=+3.2 \mathrm{~V}$ and $I=100 \mathrm{nA}$. The left pointing arrow indicates a step edge and the right pointing arrow a dislocation line.
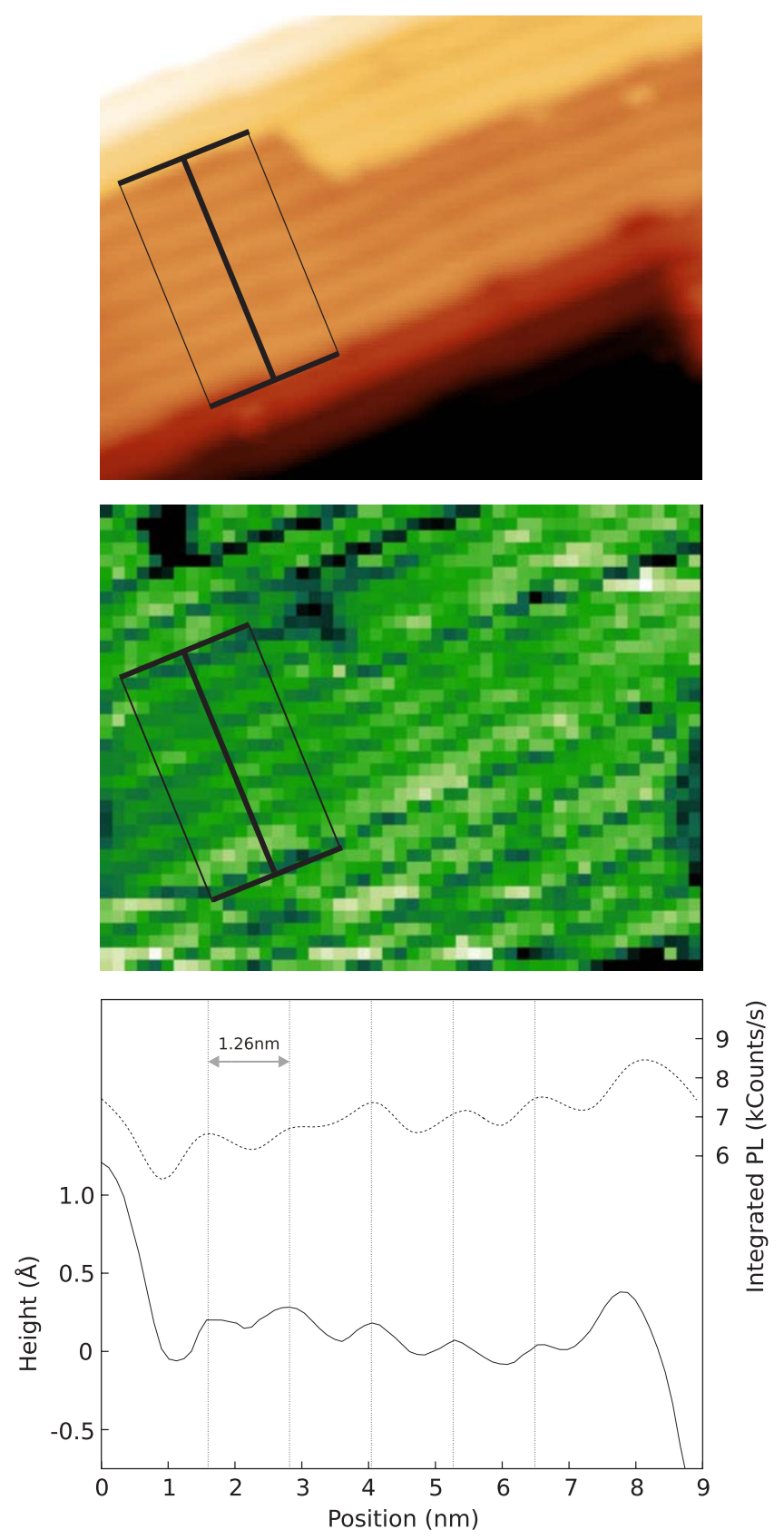

FIG. 8. (Color online) $24 \times 18 \mathrm{~nm}^{2}$ topography image (top) and photon map (middle) of the $\mathrm{Au}(110)(1 \times 3)$ surface taken at $V=+3.2 \mathrm{~V}$ and $I$ $=100 \mathrm{nA}$. The average cross section of the area indicated by the black lines of the luminescence signal (dashed) and topography signal (solid) are compared (bottom). The dotted vertical lines indicate the periodicity, $1.26 \mathrm{~nm}$ of the surface reconstruction.

rows, are attributed to different spatial distributions of the local density of states in the elastic and inelastic tunneling channels. Measurements on the $\operatorname{Au}(110)(1 \times 3)$ surface might provide evidence to support this model but this is outside the scope of the current paper.

The measurements presented in this paper show that it is possible to implement luminescence detection into a commercially available Omicron low temperature STM. With our optical system we have shown that it is possible to spectrally resolve the luminescence emission and simultaneously record photon maps and topography with atomic resolution.

We thank STW-VICI under Grant No. 6631, NAMA- 
STE, and the NanoSci-E+ project QD2D of the European Commission for their financial support.

${ }^{1}$ G. Binnig and H. Rohrer, Helv. Phys. Acta 55, 726 (1982).

${ }^{2}$ G. Binnig, H. Rohrer, C. Gerber, and E. Weibel, Phys. Rev. Lett. 50, 120 (1983).

${ }^{3}$ J. H. Coombs, J. K. Gimzewski, B. Reihl, J. K. Sass, and R. R. Schlitter, J. Microsc. 152, 325 (1988).

${ }^{4}$ J. K. Gimzewski, B. Reihl, J. H. Coombs, and R. R. Schlitter, Z. Phys. B: Condens. Matter 72, 497 (1988).

${ }^{5}$ S. F. Alvarado, P. Renaud, D. L. Abraham, C. Schönenberger, D. J. Ahrent, and H. P. Meier, J. Vac. Sci. Technol. B 9, 409 (1991).

${ }^{6}$ R. Berndt, R. Gaisch, W. D. Schneider, J. K. Gimzewski, B. Reihl, R. R. Schlittler, and M. Tschudy, Phys. Rev. Lett. 74, 102 (1995).

${ }^{7}$ X. L. Guo, D. Fujita, N. Niori, K. Sagisaka, and K. Onishi, Surf. Sci. 601, 5280 (2007).

${ }^{8}$ M. Kemerink, J. W. Gerritsen, J. G. H. Hermsen, P. M. Koenraad, H. van Kempen, and J. H. Wolter, Rev. Sci. Instrum. 72, 132 (2001).

${ }^{9}$ G. Hoffmann, T. Maroutian, and R. Berndt, Phys. Rev. Lett. 93, 076102 (2004).

${ }^{10}$ J. Frohn, J. Wolf, K. Besocke, and M. Teske, Rev. Sci. Instrum. 60, 1200 (1989).

${ }^{11}$ G. Hoffmann, J. Kröger, and R. Berndt, Rev. Sci. Instrum. 73, 305 (2002).

${ }^{12}$ Y. Khang, Y. Park, M. Salmeron, and E. R. Weber, Rev. Sci. Instrum. 70, 4595 (1999).

${ }^{13}$ I. Chizhov, G. Lee, and R. F. Willis, J. Vac. Sci. Technol. A 15, 1432
(1997).

${ }^{14}$ S. Ushioda, T. Tsuruoka, and Y. Ohizumi, Appl. Surf. Sci. 166, 284 (2000).

${ }^{15}$ D. Fujita, K. Onishi, and N. Niori, Microsc. Res. Tech. 64, 403 (2004).

${ }^{16}$ N. J. Watkins, J. P. Long, Z. H. Kafafi, and A. J. Mäkinen, Rev. Sci. Instrum. 78, 053707 (2007).

${ }^{17}$ R. Berndt, J. K. Gimzewski, and P. Johansson, Phys. Rev. Lett. 67, 3796 (1991).

${ }^{18}$ T. Umeno, R. Nishitani, A. Kasuya, and Y. Nishina, Phys. Rev. 54, 13499 (1996).

${ }^{19}$ F. Silly, A. O. Gusev, A. Taleb, F. Charra, and M. P. Pileni, Phys. Rev. Lett. 84, 5840 (2000).

${ }^{20}$ M. Sakurai and M. Aono, Phys. Rev. B 64, 045402 (2001).

${ }^{21}$ P. Dawson and M. G. Boyle, J. Opt. A, Pure Appl. Opt. 8, S219 (2006).

${ }^{22}$ Y.-H. Liau and N. F. Scherer, Appl. Phys. Lett. 74, 3966 (1999).

${ }^{23}$ M. G. Boyle, J. Mitra, and P. Dawson, Jpn. J. Appl. Phys., Part 1 45, 2119 (2006)

${ }^{24}$ R. Nishitani, T. Umeno, and A. Kasuya, Appl. Phys. A: Mater. Sci. Process. 66, S139 (1998).

${ }^{25}$ R. Berndt and J. K. Gimzewski, Phys. Rev. B 48, 4746 (1993).

${ }^{26}$ G. J. de Raad, P. M. Koenraad, and J. H. Wolter, J. Vac. Sci. Technol. B 17, 1946 (1999).

${ }^{27}$ K.-P. Bohnen and K. M. Ho, Electrochim. Acta 40, 129 (1995).

${ }^{28}$ A. Madrazo, M. Nieto-Vesperinas, and N. García, Phys. Rev. B 53, 3654 (1996).

${ }^{29}$ Y. Uehara, T. Fujita, and S. Ushioda, Phys. Rev. Lett. 83, 2445 (1999).

${ }^{30}$ Y. Uehara and S. Ushioda, Phys. Rev. B 66, 165420 (2002). 